\title{
Broadband Investment and the Threat of Regulation: Preventing Monopoly Exploitation or Infrastructure Construction?
}

\author{
ULRICH BLUM \\ Halle Institute for Economic Research \\ CHRISTIAN GROWITSCH \\ Scientific Institute for Infrastructure and Communication Services WIK \\ NIELS KRAP * \\ Halle Institute for Economic Research
}

\begin{abstract}
Recently, investments in new generation networks in Germany have been curtailed, since potential investors required this new network be unregulated. To develop a regulator's strategy that allows investments to occur but prevents monopolistic prices, we model an investor's decision problem under a threat of regulation. We show that the mere threat of a regulator's intervention may prevent supernormal profits without actual price regulation. The regulator, on the other hand, can influence both the investment decision and the investor's price via her signals on regulation probability and price.
\end{abstract}

\section{Introduction}

In summer 2005, Deutsche Telekom announced its plans to build a new generation broadband fiber optics network. The initial investment was said to be around 3 billion euros. However, Deutsche Telekom decided as a precondition for this new network not to be regulated with respect to pricing and third party access.

German regulation authorities announced their refusal to concede to Telekom's pressure. They suggested that Telekom and its competitors, mostly service providers that rent capacity from the dominant incumbent, agree on rules as how to manage access to the new infrastructure. Following this, Telekom let it be known that they were unwilling to share the new capacities with competitors, claiming that competitors should undertake the irreversible network investments (sunk costs) by themselves. Unless the new

* Contact Author. Department of Industrial Economics, Halle Institute for Economic Research, Kleine Märkerstraße 8, 06108 Halle/S., Germany. E-mail: niels.krap@iwh-halle.de We thank especially Diemo Dietrich, Axel Lindner and an anonymous referee for helpful comments and suggestions on earlier versions of this paper. 
technologically-leading infrastructure was exempted from regulation, Telekom threatened the investment to be made in other areas or countries. Hence, the German regulator faced a difficult situation: allowing Telekom to have its way may endanger future competition on next generation networks in telecommunication in Germany. However, if the regulator decided access regulation to hold, the infrastructure would not be set up.

In summary, the regulatory agency faced an issue of first and second degree errors: if she regulated an area which - from the economic point of view - should be left unregulated, such an over-regulation may foreclose welfare enhancing investments. If, however, she did not regulate an area which required regulation, under-regulation could inhibit competition and facilitate market power exploitation.

In this paper, we analyze investment decisions on new generation networks. Therefore, we model a firm's decision problem under a threat of regulation in a game-theoretical context. The decision whether to invest or not depends on the probability of regulation and its assumed impact on investment returns. Depending on the investor's expectation on these parameters, he will decide whether the investment is favorable or not, and which price is optimal. This price can be expected to be lower than a non-regulated profit maximizing price, since the potential investor presumably tries to circumvent regulation and reduce the probability of intervention, respectively. Thus, the mere threat of a regulator's intervention may prevent supernormal profits without actual price regulation. The regulator, on the other hand, can influence both investment decision and the investor's price via his signals on regulation probability and price. These signals can be considered optimal if they simultaneously allow investment and minimize the investor's price. Accordingly, wrong signals by the regulator may prevent investments. Hence, we model an investment decision under uncertainty (of regulation) to develop a welfare maximizing regulation strategy.

Previous research on the relationship between investment and regulation has discussed either impacts of specific regulatory regimes or incentives of underinvestment due to policy or market uncertainty. In his seminal work, Dixit (1991) pointed out that transparent price ceilings in a market with uncertain demand can reduce investment. Only the observation of an even higher shadow price may trigger investment in such a setting. However, as Dixit assumed a competitive market, his work does not consider investment in natural monopolies, such as is the case for particular network industries. Therefore, we extend Dixit's analysis to cover this situation. Other research on dynamic efficiency issues of regulation by Mandy and Sharkey (2003), Littlechild (2003), and Evans and Guthrie (2005) address the negative incentives on investment imposed by regulatory pricing constraints. Specifically, Evans and Guthrie consider total element long run incremental cost (TELRIC) pricing, and find that within such a pricing framework, capital asset pricing issues necessitate a risk premium for sustainable investments. Indeed, their models provide interesting insights into the investment incentives of specific regulatory regimes. However, unlike the present paper, they assume a universal service obligation as well as a general revenue regulation.

A second strand of literature discusses policy uncertainty or - more specifically regulators' ex-post opportunism (potential hold-up). Recent work on different network industries, for example, Ishi and Yan (2004), Saphores et al (2004) and Dobbs (2004) confirm the hypothesis of delayed infrastructure investments, as addressed by Teisberg (1993), who showed that rational firms may delay investment when facing uncertain or asymmetric profit and loss restrictions. However, this research has to a certain extend 
neglected welfare enhancing aspects of regulatory uncertainty and the issue of regulatory threats, which is basically the threat of governmental intervention in case of inefficient price levels. ${ }^{1}$ The intention of regulatory threat is to encourage firms to restrict their prices voluntarily (the so-called light-hand regulation approach, see Glazer and McMillan (1992), and for an overview on network industries see Haucap et al, 2006). There have been numerous applications to different network sectors (for example, of the British airport sector, see Starkie (2001), and Acutt and Elliott (2001) for the experiences of the UK electricity generation industry). Brunekreeft (2004) translates the idea of regulatory threat into the threat of ex-post antitrust intervention, whereby under certain conditions, the latter can work in similar fashion and also induce a voluntary price cap. The theoretical work on regulation by the threat of intervention has neglected to emphasize its relevance for infrastructure investment decisions, especially under asymmetric information. ${ }^{2}$ This paper fills that void. It contributes to the analysis of regulatory options for next generation networks and regulation's effects on dynamic efficiency and innovation (see, for example, Baake et al, 2005). The paper provides a feasible solution to the trade-off between static (or allocative) efficiency and dynamic (or innovative) efficiency.

The remainder of this paper is organized as follows: the analytical background and model are presented in Section 2, followed by Section 3, which discusses the results and highlights policy implications and directions for future research.

\section{Analytical background and model}

Consider a firm facing the decision of an ex-ante profitable investment in a new network. The strategic problem is that this infrastructure may be regulated in the future. What factors determine the firm's decision and how do these parameters influence the potential returns?

Suppose that the firm can choose to invest either $\hat{I}$ or nothing into a new, welfareenhancing infrastructure. This investment is a necessary precondition for selling a new service or good. Consequently, it increases market size and decreases pressure, allowing the skimming off of innovation rents by the investor. In doing so, the firm faces certain risks, in particular the risk of being regulated once others have not invested being probably the most critical one. ${ }^{3}$

\footnotetext{
${ }^{1}$ Admittedly, Sappington (1986) deals with regulatory uncertainty, although from a different perspective. He analyzes the positive effects of information asymmetries on firms' investment, not the idea of putting a company under regulatory risk, as we do.

2 There has been some research on a phenomenon called trigger price regulation, which is somewhat comparable to our approach. In a seminal article, Salant and Woroch (1992) introduce the phrase and show, given perfect information, the regulator can allow for new investments while not directly regulating. A credible commitment of not exploiting producer's rents is, however, very sensitive to their assumption of symmetric information, which is rather strong.

${ }^{3}$ Furthermore, the investing party has to bear the risks of technological obsolescence as well as simple economic default. We refrain from discussing these risks to reduce complexity but it is clear that expected future profits have to cover these too.
} 
Initially, the firm has zero marginal costs and revenues $R=R(I, p)$, where $I \in\{0, \hat{I}\}$ denotes the new investment taken by the firm and $p$ the price of the new good. The following characteristics apply to the revenue function:

- without investment $(I=0)$, revenues are independent of price, $\partial R(I=0) / \partial p=0$, and are equal to $R_{0}=R(I=0, p)$,

- with investment $(I=\hat{I})$, revenues are higher than without investment, $R_{1}(p):=R(I=\hat{I}, p)>R_{0}$ for $p>0$,

- $\quad$ with investment $(I=\hat{I})$ and increasing price, revenues rise until $p_{N R}^{*}$ (price of maximum turnover) and fall beyond that, $\frac{\partial R_{1}}{\partial p}\left\{\begin{array}{l}>0, \text { if } p<p_{N R}^{*} \\ =0, \text { if } p=p_{N R}^{*} \\ <0, \text { if } p>p_{N R}^{*}\end{array}\right.$

In case of investment, $\hat{I}$, there is an optimal price $p_{N R}^{*}$ for the investor which can thus be considered as an unregulated benchmark case. The investment is assumed to be welfare enhancing and increases investor's profit without (the threat of) regulation.

Now, the regulator faces the dilemma between enabling the infrastructure investment and avoiding super-normal profits. More precisely, she has - ideally - to define a regulation price, $p_{R}$, which just covers the total investment cost. Under asymmetric information, she does not know which investments are essential for accessing new customers and which is the level of efficient costs. Thus, the regulator is unaware of the long-run welfare maximizing price. Therefore, she can signal her acceptance of prices within a certain tolerance bracket, with $d$ expressing the distance between the regulation price and an intervention price, $\bar{p}$. For any price $p_{1}$ chosen by the investor above that upper limit $\bar{p}$, the regulator will intervene with a probability of 1 , setting the regulation price $p_{R}$.

However, if the regulator signals the intervention price perfectly, the investor would invest, setting exactly that price or - in the case of an unfavorable low intervention price neglect the investment. If the investor cannot make a perfect announcement he has two options: i) he may either invest and set a price which is above intervention price, making the regulator set the regulation price; or ii) threatened by a possible regulation, the investor sets a price which is below the intervention price. In both cases, the resulting price is lower than the intervention price and is welfare-enhancing. Therefore, the regulator has an incentive to mask her signals to a certain degree. This enables the regulator to make the investor reveal his true cost, at least to some extent. However, investment under regulatory risk may be prevented, if the firm's perception of the intervention price is below a costcovering level. Such an underinvestment should be just as well avoided as monopoly exploitation by the investor, likewise.

A necessary precondition for any kind of investment is the regulator's commitment not to hold-up the firm. In a static game, a regulator could ex-ante signal a price tolerance enabling investment. After investment, she may hold up the firm by ex-post reducing her tolerance, identifying the investor's price as intolerably high and intervening by setting the 
regulation price. This price may be set welfare maximizing, which is equal to marginal cost. Since the firm would anticipate such a lack of regulatory commitment, he may omit investing.

Therefore, the regulator has to credibly commit and refrain from usurping the firm's returns. Salant and Woroch (1992) developed a model called trigger price regulation in which they show that in a long term relationship between regulator and firm the regulator has an incentive - and the possibility - to credibly commit to cut prices down to operating costs in case of inefficient behavior only. However, Salant and Woroch do not consider the regulator's uncertainty about the firm's cost. Introducing information asymmetry in our model, we take Salant and Woroch's findings into account and consider the regulator as long lived with sufficient concern about future market developments and consumer preferences, thus preventing her from strategic hold-up.

Now, given such a benevolent regulator, the investor's decision whether to invest or not depends on his expectations about the intervention price, the regulation price and the regulator's tolerance. Technically, the firm builds up an expectation of the density function $f(d)$ of the regulator's tolerance interpreting her signals. We define $\sigma^{2}=\operatorname{Var}(d)$ as the variance of that tolerance. This variance is assumed to increase with weakening signals. Since the firm obtains information about the regulation price through signals, he can estimate a density function over the intervention price $f(\bar{p})=f\left(d+p_{R}\right)$. For any price below that price (but above the regulation price) that the firm sets, the regulator refrains from intervention, tolerating a certain deviation due to uncertainty. For any price above the intervention price, the regulator intervenes and sets the regulation price $p_{R}$.

Recapitulating, the firm ex-ante knows by assumption the regulation price but neither does he know the regulator's tolerance nor her intervention price. Therefore, depending on the signals given, the firm can only derive a density function of that intervention price. For simplicity, we assume that density function to follow a symmetric triangular distribution:

$$
f(\bar{p})= \begin{cases}\frac{\bar{p}-p_{R}}{6 \sigma^{2}} & \text {,if } p_{R} \leq \bar{p} \leq p_{R}+\sqrt{6} \sigma \\ \frac{p_{R}+2 \sqrt{6} \sigma-\bar{p}}{6 \sigma^{2}} & \text {,if } p_{R}+\sqrt{6} \sigma<\bar{p} \leq p_{R}+2 \sqrt{6} \sigma \\ 0 & \text {,if } \bar{p}<p_{R} \text { or } \bar{p}>p_{R}+2 \sqrt{6} \sigma\end{cases}
$$

The investor hence expects the regulator to intervene with a probability of $F\left(p_{1}\right)=\operatorname{prob}\left(\bar{p} \leq p_{1}\right)$, where $p_{1}$ is the firm's price after investment. That probability can be derived from the intervention price's density function and shows the following properties: 


$$
\begin{aligned}
F\left(p_{1}\right) & =\int_{0}^{p_{1}} f(x) d x \\
& = \begin{cases}\frac{\left(p-p_{R}\right)^{2}}{12 \sigma^{2}} & \text {,if } p_{1}<p_{R}, \\
1-\frac{\left(p_{R}+2 \sqrt{6} \sigma-p\right)^{2}}{12 \sigma^{2}} & \text {, if } p_{R} \leq p_{1} \leq p_{R}+\sqrt{6} \sigma, \\
1 & \text { if } p_{R}+\sqrt{6} \sigma<p_{1}<p_{R}+2 \sqrt{6} \sigma,\end{cases}
\end{aligned}
$$

The expected intervention price $\bar{p}^{e}=p_{R}+\sqrt{6} \sigma$ increases in accordance with the regulation price $p_{R}$ and with the regulator's tolerance, expressed by the variance of the density function, $\sigma^{2}$. For a given investor's price, the probability of intervention increases with a decreasing regulation price or tolerance. A perfect signal sets the variance of the expected tolerance to zero $\left(\sigma^{2}=0\right)$ and equates expected intervention price with regulator's intervention price.

Figure 1 shows the relationship between the regulation price $p_{R}$, the intervention price's density function $f(\bar{p})$ and the probability of regulation $F\left(p_{1}\right)$.

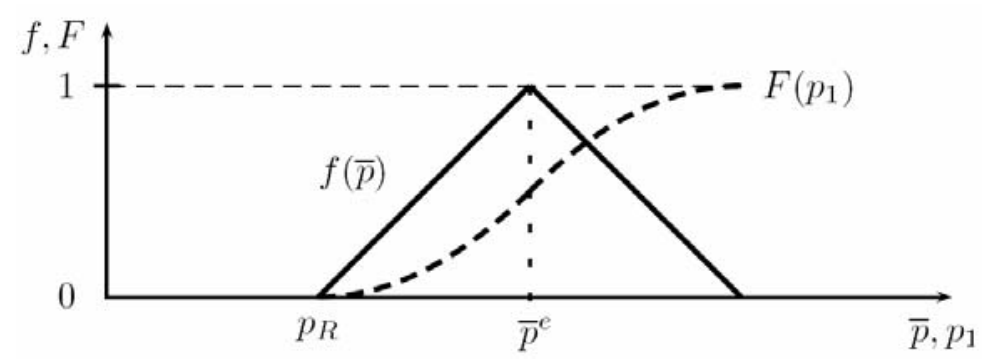

\section{Figure 1: Intervention price}

The sequence of decision in the investment game is shown in figure 2. In a first step, the regulator gives a perfect signal about the regulation price $p_{R}$ and a signal of her tolerance. Interpreting that signal, the investor develops his expectation about the intervention price's density function $f(\bar{p})$. Then he decides whether to invest or not. Deciding not to invest provides him with a profit of $\pi_{0}=R_{0}$. If he decides to invest, he will set a price $p_{1}$, causing the regulator to intervene or not. 


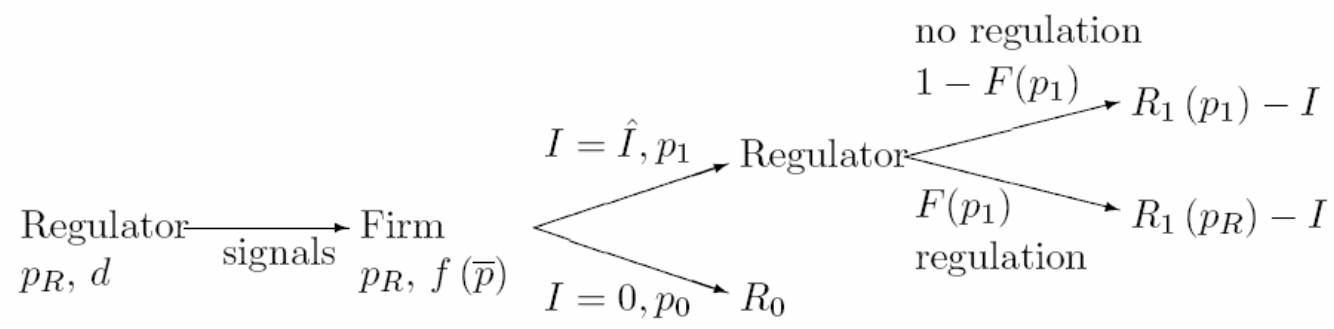

\section{Figure 2: The model}

\subsection{A market with symmetric information}

To illustrate the decision mechanism and its relevant parameters, we first analyze an investment decision under symmetric information as a benchmark. If the regulator knows about the total cost of investment, she is able to determine a minimum price $p_{1}^{* *}$, making the firm indifferent between investing and not: $R_{0}=R_{1}\left(p_{1}^{* *}\right)-\hat{I}$. To allow investment and minimize the price afterwards, the regulator sets exactly $p_{1}^{* *}$, and signals perfectly her (zero) tolerance. The firm receives that signal and calculates a probability function of regulatory intervention:

$$
F\left(p_{1}\right)=\left\{\begin{array}{l}
0, \text { if } p_{1} \leq p_{1}^{* *} \\
1, \text { if } p_{1}>p_{1}^{* *}
\end{array}\right.
$$

The optimal price after investment then is $p_{1}^{*}=p_{1}^{* *}$ : a price $p_{1}<p_{1}^{* *}$ would lead to lower revenues, hence a profit lower than without investment $R_{0}$. A price $p_{1}>p_{1}^{* *}$ on the other hand would not be accepted and would be reduced to $p_{1}^{* *}$ by the regulator. Thus, in a market with symmetric information and the regulator giving a perfect signal about the regulation price $p_{1}^{* *}$ and her tolerance of zero, the firm invests, setting exactly that price. With perfect information potential regulation - that is the threat of regulation - is equivalent to actually enforced regulation.

\subsection{A regulated market}

Introducing the realistic assumption of asymmetric information, the regulator faces the problem to decide which signal to give. To answer that question, we have to clarify the firm's incentives. His optimization problem is as follows:

(3) $\max _{I \in\{0, \hat{I}\}, p} \pi^{e}=\left\{\begin{aligned} F(p) R_{1}\left(p_{R}\right)+(1-F(p)) R_{1}(p)-I & \text {, if } I=\hat{I}, \\ R_{0} & \text {, if } I=0,\end{aligned}\right.$ 
where $\pi^{e}$ is the firm's expected profit, influenced by his investment decision and price. We denote $p_{1}^{*}$ as his optimal price under investment. The first order condition for the firm in case of investment is

$$
f\left(p_{1}^{*}\right)\left[R_{1}\left(p_{R}\right)-R_{1}\left(p_{1}^{*}\right)\right]+\left(1-F\left(p_{1}^{*}\right)\right) \frac{\partial R_{1}}{\partial p}\left(p_{1}^{*} \stackrel{!}{=} 0\right.
$$

This can be rewritten as

(4) $\left(1-F\left(p_{1}^{*}\right)\right) \frac{\partial R_{1}}{\partial p}\left(p_{1}^{*}\right)=\frac{d F\left(p_{1}^{*}\right)}{d p_{1}^{*}}\left[R_{1}\left(p_{1}^{*}\right)-R_{1}\left(p_{R}\right)\right]$.

A price increase leads to a revenue increase with a probability $1-F\left(p_{1}^{*}\right)$ (left hand side of equation (4)), hence an increase in expected revenues. ${ }^{4}$ In equilibrium, this increase has to be equal to an expected increased drop in profit due to regulation (right hand side of equation (4)).

As shown for a situation with symmetric information, the price $p_{1}^{* *}$ is defined as the break even investment (minimum) price with $R_{0}=R_{1}\left(p_{1}^{* *}\right)-\hat{I}$. Since revenues increase for any price, $p_{1}^{* *}<p<p_{N R}^{*}$, a rational investor invests if the optimal price under investment is higher than that minimum price $p_{1}^{*}>p_{1}^{* *}$.

Proposition: An investor's optimal price $p_{1}^{*}$ under investment in case of price regulation is: $p_{1}^{*}=p_{N R}^{*}$ for $\quad p_{R} \geq p_{N R}^{*} \rightarrow F\left(p_{N R}^{*}\right)=0 \quad$ or in range $p_{1}^{*} \in\left[p_{R}, \min \left\{p_{R}+\sqrt{6} \sigma, p_{N R}^{*}\right\}\right]$ with the following characteristics $\partial p_{1}^{*} / \partial p_{R}>0$ and $\partial p_{1}^{*} / \partial \sigma>0$ for $p_{R}<p_{N R}^{*}$.

In the second case, the firm's expected profits under investment increase with an increasing regulation price and a higher regulator's tolerance.

The proposition shows that the investor's optimal price is lower than the expected intervention price. Realistically, this price lies below the investor's profit maximizing price in the absence of regulation (Cournot price) ${ }^{5}$ Since the investor's optimal price (and through that - his profit) is a function of $p_{R}$ and $\sigma$, it rises with an increasing regulation price as well as with an increasing tolerance.

For the regulator, the proposition's results indicate that once uncertainty about the actual characteristics of the investment - for example, efficient costs or future earnings increases, she should either raise the regulation price or signal an increasing tolerance with respect to upward deviations from that price. However, the better the regulator is informed, the lower she may set the tolerance and the closer she can place the regulation price to the minimum investment enabling and long-run welfare maximizing price $p_{1}^{* *}$.

\footnotetext{
${ }^{4}$ Note that in case of regulation, revenues are independent of that price.

${ }^{5}$ Only if the regulator overestimates the cost of investment or underrates the expected revenues and therefore sets a regulation price above the firm's unregulated optimal price, Cournot charging would be favourable to setting the regulation price.
} 
Sappington (1986) shows that given a perfectly informed regulator, firms will have no incentive to invest in efficiency enhancing investments since the resulting cost-savings would be completely transferred to consumers. Therefore, they suggest that the regulator may abstain from better information. As we consider a regulator with long-term orientation as introduced by Salant and Woroch (1992), these results do not directly contradict our analysis. The regulator in our model allows for positive expected returns to provide an incentive for new infrastructure installation rather than holding up the firm.

In such a setting, actual regulation becomes unnecessary. The mere threat of regulation prevents monopolistic prices while it allows profitable investment - if her signals are not to restrictive and therefore foreclosing.

\section{Conclusion}

This paper has modeled the trade-off a regulator faces when a firm intends to invest into a new welfare enhancing infrastructure. On the one hand, the regulator tries to anticipate market-power exploitation, on the other hand, she has to consider that the threat of intervention may prevent the investment. Our model shows that the more the regulator's uncertainty about the lowest investment-permitting price increases, the more she should signal an increased tolerance against deviations from that regulation price. This indeed raises the intervention price and consequently, the firm's profits. Nevertheless, the mere threat of a regulatory intervention may make an investor set a tolerable price even without actual price regulation. Given the corresponding limitation of abuse of market-power, exante tolerance of super-normal profits can, from a welfare economic perspective, be considered to be preferable compared to the preventing of the investment. Moreover, the regulator could thereby reduce information asymmetries and decrease the optimal level of tolerance, resulting in a more precise intervention price and an effective regulatory threat.

Recapitulating our findings, we state that as long as the regulator is uncertain about cost and demand structure in the market of the infrastructure to be enhanced, she should not be acting too intolerantly, since such behavior may prevent a welfare increasing investment. These results are consistent with previous research on the effectiveness of regulatory threats in particular. Concerning the case of Deutsche Telekom, the German regulator should - ex ante - leave the infrastructure investment unregulated and signal the regulation price. This should encourage Deutsche Telekom to invest while preventing it from exploiting its monopolistic power. From a dynamic perspective, such a light-handed regulation may encourage additional - and competitive - infrastructure investment, increase technological development, economic welfare and make regulation redundant in the future. Therefore, our findings show that the concept of regulating by the threat of intervention is not only applicable to existing infrastructure but also to new investments as well.

This work described a regulator's optimal strategy concerning welfare enhancing infrastructure investments in a static game-theoretic setting, showing that the mere threat of regulation may be preferred to an actual regulatory intervention. Future research should analyze the effectiveness of regulatory threat on investment in a dynamic context. Additionally, demand risks could be introduced to model a more realistic investment decision. Over and above, further models should allow continuous investments and address the issue of regulation-investment sensitivity. 


\section{$4 \quad$ References}

Acutt, M. and C. Elliott (2001) “Threat-based Regulation and Endogenously Determined Punishments,” Working Paper 2001/007, Lancaster University Management School.

Baake, P., U. Kamecke and C. Wey (2005) “A Regulatory Framework for New and Emerging Markets,” Communications and Strategy, 60: 123-136.

Brunekreeft, G. (2004) "Regulatory Threat in Vertically Related Markets: The Case of German Electricity,” European Journal of Law and Economics, 17: 285-305.

Dixit, A. (1991) “Irreversible Investment with Price Ceilings," Journal of Political Economy, 99, 541-557.

Dobbs, I.M. (2004) “Intertemporal Price Cap Regulation under Uncertainty,” The Economic Journal, 114: 421-440.

Evans, L.T. and G.A. Guthrie (2005) "Risk, Price Regulation, and Irreversible Investment,” International Journal of Industrial Organization, 23: 109-128.

Glazer, A. and H. McMillan (1992) "Pricing by the Firm under Regulatory Threat," Quarterly Journal of Economics, 107: 1089-1099.

Haucap, J., U. Heimeshoff and A. Uhde (2006) "Credible Threats as an Instrument of Regulation for Network Industries,” in P.J.J. Welfens (ed.), Regulatory Changes, Innovations and Investment Dynamics, Springer: Berlin.

Ishi, J. and J. Yan (2004) "Investment under Regulatory Uncertainty: US Electricity Generation Investment since 1996,” Working Paper CSEMWP-127, Center for the Study of Energy Markets, University of California, Irvine, Ca.

Littlechild, S. (2003) "Reflections on Incentive Regulation," Review of Network Economics, 2: 289-315.

Mandy, D.M. and W.W. Sharkey (2003) "Dynamic Pricing and Investment from Static Proxy Models,” Review of Network Economics, 2: 403-439.

Salant, D.J. and G.A. Woroch (1992) “Trigger Price Regulation,” RAND Journal of Economics, 23: 29-51.

Saphores, J.-D., E. Gravel and J.-T. Bernard (2004) "Regulation and Investment under Uncertainty: An Application to Power Grid Interconnection,” Journal of Regulatory Economics, 25: 169-186.

Sappington, D.E.M. (1986) "Commitment to Regulatory Bureaucracy," Information Economics and Policy, 2: 243-258.

Starkie, D. (2001) “A New Deal for Airports?” in C. Robinson (ed.), Regulating Utilities: New Issues, New Solutions, Elgar Publisher: Cheltenham. 
Teisberg, E.O. (1993) “Capital Investment Strategies under Uncertain Regulation,” The RAND Journal of Economics, 24: 591-604.

\section{$5 \quad$ Appendix: Proof of propositions}

\section{Investor's optimal price}

Case $1, p_{R} \geq p_{N R}^{*}$ : This situation is comparable to that without regulation threat. Thus, the optimal price is $p_{1}^{*}=p_{N R}^{*}$.

Case 2, $p_{R}<p_{N R}^{*}$ : We show by contradiction, that $p_{1}^{*} \leq p_{N R}^{*}$, in a second part, that $p_{1}^{*} \leq p_{R}+\sqrt{6} \sigma$ and in a third part, that $p_{1}^{*} \geq p_{R}$.

Case $2 a, p_{1}^{*} \leq p_{N R}^{*}$. If we assume that $p_{1}^{*}>p_{N R}^{*}, p_{N R}^{*}$ would increase profits:

$$
\begin{aligned}
\pi_{1}\left(p_{1}^{*}\right) & =F\left(p_{1}^{*}\right) R_{1}\left(p_{R}\right)+\left(1-F\left(p_{1}^{*}\right)\right) R_{1}\left(p_{1}^{*}\right)-I \\
& \leq F\left(p_{N R}^{*}\right) R_{1}\left(p_{R}\right)+\left(1-F\left(p_{N R}^{*}\right)\right) R_{1}\left(p_{N R}^{*}\right)-I=\pi_{1}\left(p_{N R}^{*}\right),
\end{aligned}
$$

because

$$
\left[F\left(p_{1}^{*}\right)-F\left(p_{N R}^{*}\right)\right]\left[R_{1}\left(p_{R}\right)-R_{1}\left(p_{N R}^{*}\right)\right]-\left[1-F\left(p_{1}^{*}\right)\right]\left[R_{1}\left(p_{N R}^{*}\right)-R_{1}\left(p_{1}^{*}\right)\right]<0 .
$$

This indeed is a contradiction, hence $p_{1}^{*} \leq p_{N R}^{*}$.

Case $2 b, p_{1}^{*} \leq p_{R}+\sqrt{6} \sigma$ : If we assume that $p_{1}^{*}>p_{R}+\sqrt{6} \sigma$, then equation (3) in conjunction with equation (1) can be written as following:

$$
\begin{aligned}
\frac{p_{R}+2 \sqrt{6} \sigma-p_{1}}{6 \sigma^{2}}\left[R\left(p_{R}\right)-R\left(p_{1}\right)\right]+\frac{\left(p_{R}+2 \sqrt{6} \sigma-p_{1}\right)^{2}}{12 \sigma^{2}} \frac{\partial R_{1}}{\partial p_{1}} & =0 \\
R\left(p_{R}\right)+\frac{p_{R}+2 \sqrt{6} \sigma-p_{1}}{2} \frac{\partial R_{1}}{\partial p_{1}} & =R\left(p_{1}\right) .
\end{aligned}
$$

This equation cannot be hold because:

$$
\begin{aligned}
R\left(p_{1}\right)=R\left(p_{R}\right)+\int_{p_{R}}^{p_{1}} \frac{\partial R}{\partial x} d x & >R\left(p_{R}\right)+\left(p_{1}-p_{R}\right) \frac{\partial R}{\partial x} \\
& >R\left(p_{R}\right)+\frac{p_{R}+2 \sqrt{6} \sigma-p_{1}}{2} \frac{\partial R}{\partial x}
\end{aligned}
$$

This is a contradiction, hence $p_{1}^{*} \leq p_{R}+\sqrt{6} \sigma$. 
Case $2 c, p_{1}^{*} \geq p_{R}$ : As $p_{R}<p_{N R}$, a price $p_{1}^{*}<p_{R}$ cannot be an optimum because $\partial R_{1} / \partial p_{1}^{*}>0$

\section{Reaction of the investor's optimal price}

To proof the reaction of the investor's optimal price, we use the implicit function theorem. We write equation (4) as:

$$
g:=f\left(p_{1}^{*}\right)\left[R_{1}\left(p_{R}\right)-R_{1}\left(p_{1}^{*}\right)\right]+\left(1-F\left(p_{1}^{*}\right)\right) \frac{\partial R_{1}}{\partial p_{1}}\left(p_{1}^{*}\right) \stackrel{!}{=} 0 .
$$

At first, we will proof that $\partial g / \partial p_{1}^{*}>0$ and analyze how $g$ reacts on $p_{R}$ and $d$ after that.

Reaction of $g$ to $p_{1}^{*}$ : From the proof of the investor's optimal price (Case 2c), we know that $p_{1}^{*} \leq p_{R}+\sqrt{6} \sigma$. Thus,

$$
\frac{\partial g}{\partial p_{1}^{*}}=\overbrace{\frac{d f}{d p_{1}}\left(p_{1}^{*}\right)\left[R_{1}\left(p_{R}\right)-R_{1}\left(p_{1}^{*}\right)\right]}^{\leq 0}-\overbrace{2 f\left(p_{1}^{*}\right) \frac{\partial R_{1}}{\partial p}\left(p_{1}^{*}\right)}^{\geq 0}+\overbrace{\left(1-F\left(p_{1}^{*}\right)\right) \frac{\partial^{2} R_{1}}{\partial p_{1}^{2}}\left(p_{1}^{*}\right)}^{<0}<0 .
$$

Change in expectations regarding the regulating price:

$$
\begin{aligned}
& \frac{\partial g}{\partial p_{R}}=\overbrace{\frac{\partial f}{\partial p_{R}}\left(p_{1}^{*}\right)\left[R_{1}\left(p_{R}\right)-R_{1}\left(p_{1}^{*}\right)\right]}^{\geq 0}+\overbrace{f\left(p_{1}^{*}\right) \frac{\partial R_{1}}{\partial p_{R}}\left(p_{R}\right)}^{\geq 0}-\overbrace{\frac{\partial F}{\partial p_{R}}\left(p_{1}^{*}\right) \frac{\partial R_{1}}{\partial p_{1}}\left(p_{1}^{*}\right)}^{\leq 0}>0 \\
& \quad \text { leads to } \frac{\partial p_{1}^{*}}{\partial p_{R}}=-\frac{\partial g}{\partial p_{R}} / \frac{\partial g}{\partial p_{1}^{*}}>0 .
\end{aligned}
$$

Change in the expected tolerance:

$$
\begin{aligned}
& \frac{\partial g}{\partial \sigma}=\overbrace{\frac{\partial f}{\partial \sigma}\left(p_{1}^{*}\right)\left[R_{1}\left(p_{R}\right)-R_{1}\left(p_{1}^{*}\right)\right]}^{\geq 0}-\overbrace{\frac{\partial F}{\partial \sigma}\left(p_{1}^{*}\right) \frac{\partial R_{1}}{\partial p_{1}}\left(p_{1}^{*}\right)}^{\leq 0}>0 \\
& \text { leads to } \frac{\partial p_{1}^{*}}{\partial \sigma}=-\frac{\partial g}{\partial \sigma} / \frac{\partial g}{\partial p_{1}^{*}}>0 .
\end{aligned}
$$

\section{Reaction of the expected profit after the regulation price increases}

We define $p_{1}^{* 1}$ as the price chosen by the investor and $\pi_{1}^{e 1}$ as the expected profit in case of the regulation price $p_{R}^{1}$. Furthermore, we specify $p_{1}^{* 2}$ as the price chosen by the 
investor and $\pi_{1}^{e 2}$ as the expected profit in the case of the regulation price $p_{R}^{2}$ with $p_{R}^{1}<p_{R}^{2}$. The following can be reasoned:

$$
\begin{array}{rlr}
\pi_{1}^{e 1}\left(p_{1}^{* 1}\right) & =F^{1}\left(p_{1}^{* 1}\right) R_{1}\left(p_{R}^{1}\right)+\left(1-F^{1}\left(p_{1}^{* 1}\right)\right) R_{1}\left(p_{1}^{* 1}\right)-I & \\
& \leq F^{2}\left(p_{1}^{* 1}\right) R_{1}\left(p_{R}^{1}\right)+\left(1-F^{2}\left(p_{1}^{* 1}\right)\right) R_{1}\left(p_{1}^{* 1}\right)-I & \\
& <F^{2}\left(p_{1}^{* 1}\right) R_{1}\left(p_{R}^{2}\right)+\left(1-F^{2}\left(p_{1}^{* 1}\right)\right) R_{1}\left(p_{1}^{* 1}\right)-I & =\pi_{1}^{e 2}\left(p_{1}^{* 1}\right) \\
& & \leq \pi_{1}^{e 2}\left(p_{1}^{* 2}\right),
\end{array}
$$

because $\partial F / \partial p_{R} \leq 0, R_{1}\left(p_{R}^{1}\right)<R_{1}\left(p_{1}^{* 1}\right)$ and $R_{1}\left(p_{R}^{1}\right)<R_{1}\left(p_{R}^{2}\right)$.

\section{Reaction of the expected profit after an increase of the regulator's tolerance}

Analogues to the previous, we define $p_{1}^{* 1}$ as the price chosen by the investor and $\pi_{1}^{e 1}$ as the expected profit in the case of expected tolerance $\sigma^{1}$. Furthermore, we specify $p_{1}^{* 2}$ as the price chosen by the investor and $\pi_{1}^{e 2}$ as the expected profit in the case of the expected tolerance $\sigma^{2}$ with $\sigma^{1}<\sigma^{2}$. The following can be reasoned:

$$
\begin{array}{rll}
\pi_{1}^{e 1}\left(p_{1}^{* 1}\right) & =F^{1}\left(p_{1}^{* 1}\right) R_{1}\left(p_{R}\right)+\left(1-F^{1}\left(p_{1}^{* 1}\right)\right) R_{1}\left(p_{1}^{* 1}\right)-I & \\
& \leq F^{2}\left(p_{1}^{* 1}\right) R_{1}\left(p_{R}\right)+\left(1-F^{2}\left(p_{1}^{* 1}\right)\right) R_{1}\left(p_{1}^{* 1}\right)-I & =\pi_{1}^{e 2}\left(p_{1}^{* 1}\right) \\
& & \leq \pi_{1}^{e 2}\left(p_{1}^{* 2}\right),
\end{array}
$$

because $\partial F / \partial \sigma \leq 0$ and $R_{1}\left(p_{R}\right)<R_{1}\left(p_{1}^{* 1}\right)$. 